\title{
Surgical management of polycystic liver disease
}

\author{
Robert T Russell, C Wright Pinson
}

Robert T Russell, C Wright Pinson, Vanderbilt University Medical Center, Department of Hepatobiliary Surgery and Liver Transplantation, $130122^{\text {nd }}$ Avenue South, Nashville, TN 37232-5545, United States

Supported by an educational grant from Novartis Pharmaceuticals

Correspondence to: C Wright Pinson, MD, MBA, Vanderbilt University Medical Center, Department of Hepatobiliary Surgery and Liver Transplantation, 1301 22nd Avenue South, Nashville, TN 37232-5545, United States. wright.pinson@vanderbilt.edu

Telephone: +1-615-3439324 Fax: +1-615-3436478

Received: July 13, 2007

Revised: August 2, 2007

\begin{abstract}
Adult polycystic liver disease (PCLD) is an autosomal dominant condition commonly associated with autosomal dominant polycystic kidney disease (ADPKD). However in the last decade, it has been recognized that there is a distinct form of autosomal dominant PCLD that arises without concomitant ADPKD. Early knowledge of the pathogenesis was gained from the study of hepatic cysts in patients with ADPKD. Bile duct overgrowth after embryogenesis results in cystic hepatic dilatations that are known as biliary microhamartomas or von Meyenburg complexes. Further dilatation arises from cellular proliferation and fluid secretion into these cysts. There is a variable, broad spectrum of manifestations of PCLD. Although PCLD is most often asymptomatic, massive hepatomegaly can lead to disabling symptoms of abdominal pain, early satiety, persistent nausea, dyspnea, ascites, biliary obstruction, and lower body edema. Complications of PCLD include cyst rupture and cyst infection. Also, there are associated medical problems, especially intracranial aneurysms and valvular heart disease, which clinicians need to be aware of and evaluate in patients with PCLD. In asymptomatic patients, no treatment is indicated for PCLD. In the symptomatic patient, surgical therapy is the mainstay of treatment tailored to the extent of disease for each patient. Management options include cyst aspiration and sclerosis, open or laparoscopic fenestration, liver resection with fenestration, and liver transplantation. The surgical literature discussing treatment of PCLD, including techniques, outcomes, and complication rates, are summarized in this review.
\end{abstract}

(c) 2007 WJG. All rights reserved.

Key words: Polycystic liver disease; Fenestration; Laparoscopy; Liver resection; Liver transplantation

Russell RT, Pinson CW. Surgical management of polycystic liver disease. World J Gastroenterol 2007; 13(38): 5052-5059

http://www.wjgnet.com/1007-9327/13/5052.asp

\section{INTRODUCTION}

Adult polycystic liver disease (PCLD) was first described in 1856 by Bristowe in association with autosomal dominant polycystic kidney disease (ADPKD ${ }^{[1]}$. PCLD is a rare (incidence $<0.01 \%$ ) dominantly inherited disorder characterized by multiple diffuse cystic lesions of the liver parenchyma. An asymptomatic enlarged liver is usually the hallmark of the disease. However with more effective treatment of renal disease, increasing numbers of patients are living long enough to experience symptoms from their associated polycystic liver disease. Significant symptoms or complications from liver involvement can occur in up to 20 percent of cases $^{[2,3]}$. In symptomatic PCLD patients, surgical therapy is the mainstay of therapy including laparoscopic or open fenestration with or without hepatic resection and orthotopic liver transplantation. The surgical therapy should be tailored to the extent of disease in each patient. In this review, we will summarize the literature addressing the clinical presentation, associated medical problems, and appropriate surgical management of patients with adult polycystic liver disease.

\section{PATHOGENESIS AND GENETIC BASIS OF POLYCYSTIC LIVER DISEASE}

Although there is an isolated form of polycystic liver disease, knowledge concerning the pathogenesis of hepatic cysts was gained from the study of hepatic cysts in ADPKD. These lesions have been attributed to bile duct overgrowth after the arrest of embryogenesis and failure of the intralobar bile ducts to involute. This involutional failure results in cystic dilations that are known as biliary microhamartomas or von Meyenburg complexes (VMC) ${ }^{[4]}$. Further study of these VMC confirmed that they maintain communication with the biliary tree $\mathrm{e}^{[5,6]}$. The growth of cysts in the liver is thought to arise from cell proliferation, solute and fluid secretion into the cysts, and expansion of abnormal cell matrices. Perrone and colleagues demonstrated, via culture derived epithelial cell lines, that these cysts are of biliary origin ${ }^{[7]}$. Morphological studies demonstrate that the peripheral cysts arise from biliary microhamartomas, but the centrally located cysts arise from dilatation of the peribiliary glands in the liver ${ }^{[8]}$.

ADPKD is one of the most commonly inherited diseases with an incidence of 1 in 400 to 1 in 1000. It is 

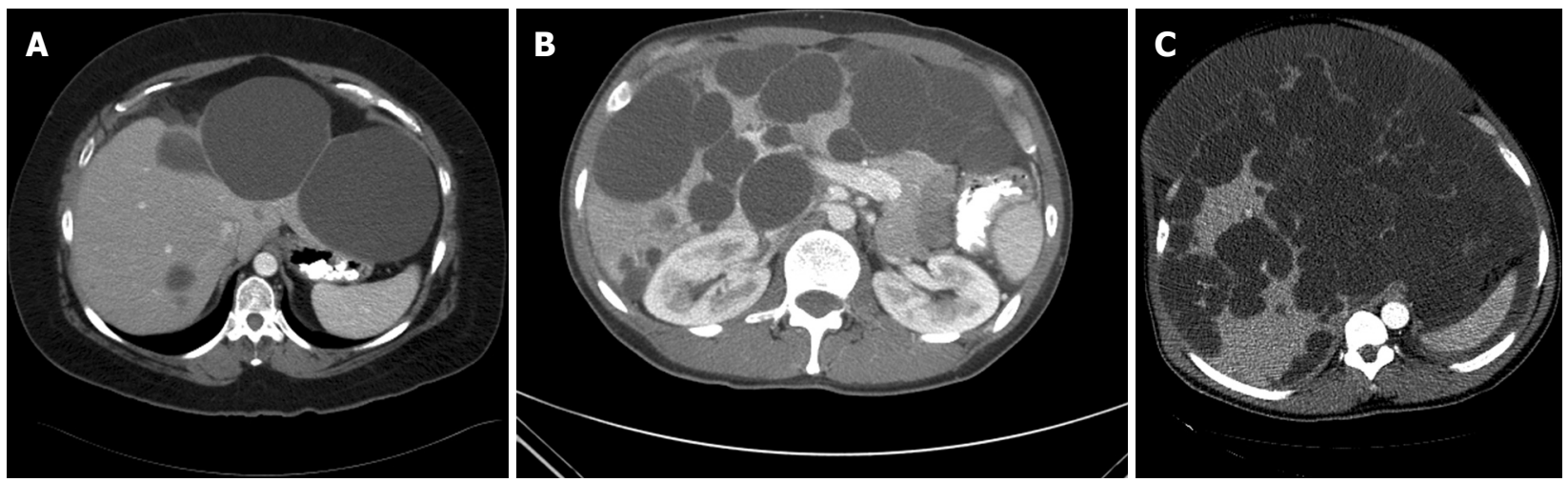

Figure 1 A: Type I PCLD; B: Type II PCLD; C: Type III PCLD.

a cause of $8 \%-10 \%$ of all chronic end-stage renal failure requiring dialysis ${ }^{[9]}$. The number of ADPKD patients with hepatic involvement appears to be rising, likely due to increased life expectancy from improved renal replacement therapy and renal transplantation. Early literature suggested that $40 \%-50 \%$ of patients with ADPKD had polycystic liver disease ${ }^{[10,11]}$, but in more recent literature, this figure has increased to $75 \%-90 \%{ }^{[12]}$. Independent risk factors for hepatic involvement in the ADPKD include advancing patient age, female gender, and severity of renal disease. The increased prevalence in females may be due to stimulatory effects of estrogen. The reported prevalence of hepatic cysts in female patients with ADPKD ranges from $58 \%$ to $75 \%$ while the prevalence in male patients ranged from $42 \%$ to $62 \%{ }^{[13]}$. Further support for the stimulatory effect of estrogen comes from studies showing an increase in liver cyst volume in pregnant women and women receiving postmenopausal estrogen therapy $y^{[14]}$. Finally, a correlation has been established between an increasing burden of hepatic cysts in patients as the severity of renal cystic disease increases ${ }^{[13]}$.

The first suggestions of an isolated form of polycystic liver disease were made in the mid-1980's ${ }^{[15,16]}$ and confirmation that there was a distinct autosomal dominant polycystic liver disease (ADPLD) occurred in the late 1990 's ${ }^{[17,18]}$. ADPLD, much rarer than its PKD counterpart, has a reported incidence of less than $0.01 \%$. ADPLD is linked to a mutation on chromosome 19 that leads to a mutated protein hepatocystin which may play a role in abnormal biliary cell proliferation and differentiation ${ }^{[1,20]}$.

\section{CLINICAL PRESENTATION}

In $80 \%$ of patients, PCLD is asymptomatic ${ }^{[2,3]}$ and often diagnosed incidentally during work-up of other clinical problems. In patients with long-standing disease, the most frequent symptoms are abdominal pain, early satiety, nausea and vomiting, supine shortness of breath, lower body edema, biliary obstruction, and ascites. These symptoms are usually indicative of significant hepatic enlargement or compression of adjacent structures, but rarely can be from infection or malignant transformation ${ }^{[21,22]}$. Laboratory studies including bilirubin, hepatic transaminases (AST and ALT), alkaline phosphatase, and gamma glutamyl transferase (GGT) are usually normal in asymptomatic patients. In symptomatic patients undergoing evaluation, alkaline phosphatase and GGT may be elevated in up to $47 \%$ and $70 \%$ of patients respectively ${ }^{[21,23-25]}$. AST may be elevated in up to $27 \%$ of patients and bilirubin levels may be elevated in up to $15^{[21,23]}$.

\section{CLASSIFICATION OF APLD}

Gigot and coauthors have described a detailed classification scheme for patients with polycystic liver disease based on pre-operative computed tomography (CT). This description is based on the number and size of cysts as well as the amount of residual normal liver parenchyma between the cysts ${ }^{[25]}$. Type I patients have a limited number $(<10)$ of large cysts with large areas of non-cystic parenchyma (Figure 1A). Patients with Type II PCLD have diffuse involvement of liver parenchyma by medium sized cysts with remaining large areas of noncystic parenchyma (Figure 1B). Finally, Type III patients are characterized by massive, diffuse involvement of liver parenchyma by small and medium sized liver cysts and only a few areas of normal liver parenchyma between cysts (Figure 1C). This classification system offers a good platform for comparison of morphological disease between patients and their classification can aid us in formulating appropriate plans for therapy.

\section{HEPATIC COMPLICATIONS OF POLYCYSTIC LIVER DISEASE}

Hepatic complications from polycystic liver disease (PCLD) typically occur only in the setting of significant hepatomegaly. These cases usually present with a palpable abdominal mass, significant abdominal pain, early satiety, or dyspnea. Occasionally, severe abdominal pain will result from rupture of a hepatic cyst, hemorrhage into a cyst or if a cyst becomes infected ${ }^{[2,26]}$. Despite longstanding polycystic liver involvement, only rarely does this entity lead to hepatic insufficiency or failure. The displaced hepatic parenchyma still functions quite well.

An infected hepatic cyst is a serious, but rare, complication. These patients will usually present with fever, leukocytosis, and right upper quadrant pain. This 
acute presentation should be suspected in this population and treated early to prevent progression to bacteremia, sepsis, and death. The morbidity and mortality rates of a cyst infection have been reported at 3\% and $2 \%$ respectively ${ }^{[27]}$. Thus there should be early institution of antibiotics and a drainage procedure. Telenti and coauthors reviewed outcomes of patient's with infected hepatic cysts and strongly supported the use of antibiotics and a drainage procedure ${ }^{[28]}$. In their review of 14 patients with infectious complications involving hepatic cysts, seven of the fourteen patients received antibiotics alone. Of these patients, two died without having a drainage procedure, four patients underwent drainage after their symptoms persisted through antibiotic therapy, and one patient was not offered drainage due to the difficult location of the infected cyst. In the seven patients treated with combined drainage and antibiotics, one patient died from postoperative sepsis and one died from unrelated causes, while five patients had no reported morbidity from their procedures. While this literature favors antibiotic therapy along with drainage, it is often difficult to determine which cyst(s) is/are actually infected. Imaging studies can often direct us toward an area of suspicion. On CT scanning, the finding of fluid-fluid levels within cysts, cystic wall thickening, or intracystic bubbles have been associated with infection of a hepatic cyst ${ }^{[28,29]}$. Ultimately drainage of the suspected cyst provides the definitive answer whether this is from the open approach or percutaneously. In those cases where the cyst is too small or cannot be accurately identified on preoperative imaging, broad spectrum antibiotics should be instituted with narrowing of the spectrum if blood cultures implicate a specific organism ${ }^{[28]}$.

Rarely, jaundice occurs as a result of cystic compression of the biliary system. This manifests as a result of the normal progression of cyst growth and compression of the common hepatic duct or common bile duct ${ }^{[30]}$. Relief of this obstruction is accomplished by surgical decompression or resection of the offending cysts.

\section{ASSOCIATED MEDICAL CONDITIONS}

Intracranial aneurysms and their association with ADPKD have been described ${ }^{[9,31]}$. There also may be increased risk for intracranial aneurysm, rupture, or dissection with ADPLD. Geevargheese and colleagues estimated the prevalence of intracranial aneurysms within this population to be $10 \%$. Because cerebral aneurysms can be a source of morbidity and mortality in these patients, they recommended screening by magnetic resonance angiography (MRA) or computed tomographic angiography (CTA) in all patients with PCLD ${ }^{[32]}$. Also, Qian and coauthors reported an association between ADPLD and increased risk for intracranial aneurysms. In their cohort, six percent of patients with genetically confirmed ADPLD were found to have either intracranial aneurysm or dissection ${ }^{[33]}$. Although there are no definitive recommendations, these reports should encourage screening radiography and treatment prior to any surgical intervention for their PCLD.

Other associated medical conditions with ADPKD and ADPLD that clinicians should be aware of are valvular heart disease and pancreatic cysts. Classically, the valvular disease most frequently described has been mitral valve prolapse and mitral valve incompetence. In their clinical profile of ADPLD patients, Qian et al estimated that mitral valve prolapse occurred in up to $26 \%$ of ADPLD patients and mitral valve incompetence in up to $31 \%$ of this population ${ }^{[33]}$. This indicates cardiac evaluation in patients with ADPLD. Finally, patients with ADPKD may have asymptomatic cysts within multiple organs, including the pancreas, spleen, ovaries, and lungs. Pancreatic cysts are the most common of the extrarenal cysts with a reported incidence of $9 \%$ among ADPKD patients over 30 years $^{[34-36]}$.

\section{THERAPEUTIC OPTIONS FOR APLD}

The primary aims of surgical therapy for polycystic liver disease should be to significantly reduce the size of the polycystic liver without compromising liver function, and to provide long-term relief of symptoms. There is no clear consensus regarding the optimum timing of intervention and the surgical approach is based in part on the number, size, and location of the cysts. All patients should be carefully evaluated for significant symptoms and degree of disability, as well as the degree of hepatic and renal dysfunction that could affect morbidity and mortality. In addition, patients should be made aware of the risk and limitations of the surgery prior to proceeding with any surgical management.

In high risk patients and those with a large dominant cyst, percutaneous aspiration and sclerosis of cysts has been proposed as a feasible option but is associated with higher recurrence rates ${ }^{[37-39]}$. Surgical options include: laparoscopic fenestration and/or resection, open fenestration and/or resection, and liver transplantation.

\section{FENESTRATION}

Prior to the advent of laparoscopic techniques, open fenestration was the standard therapy for patients with symptomatic PCLD. The technique of fenestration was first described by Lin and coauthors in $1968^{[40]}$. This technique involves de-roofing and performing the widest possible excision of the cyst wall back to the interface of the liver parenchyma. This approach allows visualization, fenestration, and drainage of superficial and deeply seated cysts within the hepatic parenchyma and internal drainage within the peritoneal cavity. The site of fenestration must be carefully selected to avoid any bleeding or leakage of bile. Destruction of the fluid producing epithelial cyst lining, with cautery or Argon beam coagulation, may be helpful to reduce continual fluid loss from the fenestrated cysts. Patients, having type I PCLD, with superficial and large cysts of limited number are the best candidates for this procedure.

With the introduction of laparoscopy, there are increasing numbers of reports of laparoscopic fenestration of patients with PCLD ${ }^{[24,25,41-46]}$. It can be performed with similar morbidity and mortality as the open fenestration, but this approach must be utilized in the appropriate population. Patients with majority of their cysts in segments VI, VII, and often VIII (when there is marked 
Table 1 Open and Laparoscopic fenestration for polycystic liver disease

\begin{tabular}{|c|c|c|c|c|c|c|c|}
\hline Reference & No. of patients & Technique $(n)$ & Mortality (\%) & Morbidity (\%) & $\begin{array}{c}\text { Mean follow-up } \\
(\mathrm{mo})\end{array}$ & $\begin{array}{l}\text { Rate of symptom } \\
\text { recurrence (\%) }\end{array}$ & $\begin{array}{l}\text { Re-operation } \\
(\%)\end{array}$ \\
\hline $\operatorname{Lin}^{[40]}$ & 3 & Open & 0 & 0 & 32 & 0 & 0 \\
\hline Van Erpecum ${ }^{[21]}$ & 9 & Open & $1(11)$ & 0 & 48 & 0 & 0 \\
\hline Turnage $^{[47]}$ & 5 & Open & $1(20)$ & $1(20)$ & 10 & 40 & 0 \\
\hline Sanchez ${ }^{[67]}$ & 7 & Open & 0 & NR & 18 & 57 & 0 \\
\hline Farges $^{[68]}$ & 13 & Open & 0 & $9(69)$ & 84 & 23 & 0 \\
\hline \multirow[t]{2}{*}{ Gigot $^{[25]}$} & 10 & Open (9) & 0 & $6(60)$ & 73 & 11 & 11 \\
\hline & & Lap (1) & 0 & 0 & & 0 & 0 \\
\hline \multirow[t]{2}{*}{ Koperna $^{[41]}$} & 39 & Open (34) & 0 & NR & 75 & 21 & 21 \\
\hline & & Lap (5) & 0 & NR & & 0 & 0 \\
\hline \multirow[t]{2}{*}{ Morino $^{[42]}$} & 9 & Lap (9) & 0 & $4(44)$ & NR & 40 & NR \\
\hline & & Conv. (2) & & & & & \\
\hline Kabbej $^{[24]}$ & 13 & Lap (13) & 0 & $7(54)$ & 26 & 72 & 23 \\
\hline \multirow[t]{2}{*}{ Martin $^{[43]}$} & 13 & Open (6) & 0 & $2(33)$ & 96 & 20 & 20 \\
\hline & & Lap (7) & 0 & $2(29)$ & 37 & 71 & 71 \\
\hline \multirow[t]{2}{*}{ Katkhouda ${ }^{[44]}$} & 9 & Lap (9) & 0 & $3(33)$ & 30 & 11 & 11 \\
\hline & & Conv. (1) & & & & & \\
\hline Fiamingo $^{[45]}$ & 6 & Lap & 0 & $3(50)$ & $1-67^{1}$ & 25 & 0 \\
\hline Marks $^{[46]}$ & 6 & Lap & 0 & $4(67)$ & $2-72^{1}$ & 14 & 0 \\
\hline
\end{tabular}

Lap: Laparoscopic; Conv: Converted from Laparoscopic to Open; NR: Not reported. ${ }^{1}$ Follow-up range in months.

hepatomegaly) and patients with deeply seated cysts that are difficult to visualize and fenestrate with laparoscopy may be better candidates for open fenestration. From the published series, these patients have a higher recurrence rate after laparoscopic fenestration due to the inability to adequately fenestrate all of their cysts ${ }^{[2,43,46]}$. The 13 published series describing open and/or laparoscopic fenestration are summarized in Table 1.

Koperna and colleagues reported the largest series of patients who underwent open or laparoscopic fenestration for PCLD. In their series, thirty-nine out of forty-four patients underwent a fenestration (34 open and 5 laparoscopic) for their symptomatic polycystic liver disease, while the other four underwent hepatic resection. In their experience, those patients with multiple cysts of $5 \mathrm{~cm}$ or greater had a higher likelihood of recurrence as compared with patients having fewer and smaller cysts ( $27 \%$ vs $13 \%$ ). They performed both techniques of fenestration with no mortalities and commented that the most common morbidity was post-operative ascites. They had a mean follow-up of seventy-five months with similar overall recurrence rates between the open and laparoscopic groups (13\% vs 11\%). They concluded that in the appropriate PCLD patients, laparoscopic fenestration should replace open fenestration because it has similar rates of success along with similar morbidity and mortality rates $^{[41]}$. Hepatic resection should be reserved for those patients with massive enlargement of the liver that would not benefit from simple fenestration. Combining all patients undergoing open or laparoscopic fenestration (Table 1), there was an overall high morbidity and low mortality rate of $30 \%$ and $1 \%$, respectively. Despite an adequate fenestration, there is a moderate recurrence of symptoms and rate of re-operation (Table 1). There must be a careful evaluation of the extent of each patient's disease to determine whether fenestration alone or resection with fenestration should be recommended.

\section{HEPATIC RESECTION WITH FENESTRATION}

The combination of hepatic resection with fenestration appears to be a valuable option for those patients with symptomatic PCLD and more severe parenchymal involvement. Most of these patients are classified as Type II or III PCLD, based on Gigot's classification ${ }^{[25]}$. Fenestration alone in this group is rarely successful because the liver parenchyma is more rigid due to the fibrosis around the cysts and the cysts do not collapse as expected after fenestration. However, combined fenestration and resection allows for the removal of multiple segments that are grossly affected and allows for reduction in liver mass. Likewise, the large superficial and deep-seated cysts within remnant segments with more normal parenchyma can also undergo fenestration. The 10 published series are reviewed in Table 2.

The largest experience is reported by Que et al in a long-term follow up of 31 patients. The majority of the patients in this group had more severe parenchymal involvement (type II and III PCLD) necessitating resection combined with fenestration. The extent and type of liver resection depended on severity of disease with 13 patients undergoing lobectomies, 2 undergoing extended liver resections, and 16 non-anatomic liver resections. An average of 4 liver segments were resected per patient with an average weight of the resected tissue being $3.9 \mathrm{~kg}$ $(8.6 \mathrm{lbs})^{[23]}$. Their mortality rate was $3 \%$ which is consistent with the other larger reported series which range from 3\%-10\% (Table 2). Despite a low mortality rate, the morbidity rates associated with this procedure are high and must be considered. This series reported a morbidity rate of $58 \%$, while in other series the morbidity rates range from $20 \%$ to $100 \%$. The most commonly reported morbidities are ascites, pleural effusions, transient biliary leaks, bleeding, and wound 
Table 2 Hepatic resection with and without fenestration for polycystic liver disease

\begin{tabular}{|c|c|c|c|c|c|c|c|}
\hline Author & No. of patients & Technique (n) & Mortality (\%) & Morbidity (\%) & $\begin{array}{l}\text { Mean follow- } \\
\text { up (mo) }\end{array}$ & $\begin{array}{l}\text { Rate of symptom } \\
\text { recurrence }(\%)\end{array}$ & $\begin{array}{l}\text { Re-operation } \\
(\%)\end{array}$ \\
\hline Turnage $^{[47]}$ & 3 & Fen \& Res & $2(67)$ & $2(67)$ & 9.6 & 33 & 0 \\
\hline Vauthey $^{[2]}$ & 5 & Fen \& Res & 0 & $5(100)$ & 14 & 0 & 0 \\
\hline Henne-Bruns $s^{[48]}$ & 8 & Fen \& Res & 0 & $3(38)$ & 15 & 50 & 0 \\
\hline Que $^{[23]}$ & 31 & Fen \& Res & $1(3)$ & $18(58)$ & 28 & 3 & 0 \\
\hline Soravia ${ }^{[49]}$ & 10 & Fen \& Res & $1(10)$ & $2(20)$ & 68 & 33 & 11 \\
\hline Koperna $^{[41]}$ & 5 & Fen \& Res & 0 & NR & NR & 0 & 0 \\
\hline $\operatorname{Martin}^{[43]}$ & 9 & Res & 0 & $6(67)$ & 9 & 33 & 0 \\
\hline Vons $^{[50]}$ & 12 & Res & $1(8)$ & $10(83)$ & 34 & 17 & 0 \\
\hline Hansman $^{[51]}$ & 2 & Res & 0 & 0 & NR & 100 & 0 \\
\hline Yang $^{[52]}$ & 7 & Fen \& Res & 0 & $7(100)$ & 20 & 100 & 0 \\
\hline
\end{tabular}

Fen: Fenestration; Res: Resection; NR: Not reported.

infection $^{[2,43,47-52]}$. Que and coauthors had excellent results with an extremely low recurrence rate with 30 out of 31 patients remaining asymptomatic at a median follow-up of 28 mo. Importantly, they felt the extent of resection and fenestration was important for good long term outcomes. Overall, most of these patients had an improvement in their quality of life and functional status without deterioration in their hepatic or renal function ${ }^{[23]}$. Although there are high morbidity rates, resection and fenestration provides patients' with severe parenchymal involvement an opportunity for symptomatic and clinical improvement with an acceptable recurrence rate.

\section{LIVER TRANSPLANTATION}

Liver transplantation as treatment for advanced PCLD, while more accepted in recent literature, still has a limited role in management of these patients. Although a majority of PCLD patients have normal liver function, orthotopic and living donor liver transplantation have been successfully utilized in the treatment of symptomatic PCLD ${ }^{[53-64]}$. Aspiration, fenestration, or surgical resection can provide adequate palliation to those patients with large single cysts or dominant disease in one lobe, but the treatment of small, truly diffuse, cystic type PCLD may well require transplantation. Total hepatectomy and liver transplantation offers the chance of definitive treatment for this disease, but may be considered drastic, considering the absence of liver failure, the potential morbidity and mortality, and the organ shortage. In their early report of transplantation for PCLD, Starzl and colleagues described a "syndrome of lethal exhaustion" as the major indication to offer transplantation to these patients ${ }^{[53]}$. These patients often reach the end of their functional lives, have intractable pain, and have a severely diminished quality of life. Indications for transplantation include cachexia, weight loss, recurrent cyst infections, portal hypertension, and ascites. Early reports have proposed these patients not wait until endstage complications of their PCLD become manifest before offering the option of transplantation ${ }^{[56,58,59]}$. Transplantation in those with end-stage PCLD, exhibited by severe disability, weakness, and malnutrition, has been shown to have higher infection-related mortality in early liver transplant series ${ }^{[56,59]}$. Performing earlier transplantation in appropriate candidates would seem to offer a greater chance of improved outcomes, meaningful recovery, and return to their prior functional status and quality of life. Furthermore, patients who have undergone prior more conservative therapies (aspiration, sclerosis, fenestration, or resection) may have postsurgical changes that make transplantation much more difficult ${ }^{[53,58,59]}$.

The option of transplantation should be balanced against the risks of surgery, long-term immunosuppression, and the need for concurrent or subsequent renal transplantation in those with ADPKD. Thus, transplantation should be limited to those patients with Type II/III PCLD with diffuse, small cystic disease that would not benefit from previously described therapies. Although the first reports of transplantation for PCLD by Kwok et $a l^{[65]}$ and Starzl et al ${ }^{[53]}$ occurred in the early 1990's, eleven to reflect studies in Table 3 describing transplantation for PCLD (Table 3). Two of the largest series reported by Lange et al and Pirenne et al report the outcomes of transplantation for PCLD in 17 and 16 patients, respectively ${ }^{[5,59]}$. Lang and coauthors reported symptomatic relief in all patients following transplantation; however they did have 5 mortalities $(29 \%)$ in their series. All five of these patients had severe anorexia, physical exhaustion, and evidence of malnutrition from end-stage PCLD prior to transplant and had postoperative infectious complications leading to their mortality. These deaths occurred at a mean of $41 \mathrm{~d}^{[56]}$. Pirenne and colleagues reviewed their experience of 16 patients undergoing liver transplantation for severe PCLD. They reported two mortalities (12.5\%): one intraoperative death from bleeding and air emboli in a patient who had undergone previous resection, and a second late death from post-transplant lung cancer. Patient and graft survival rates were $87.5 \%$ with follow-up from 3 mo to 10 years ${ }^{[59]}$. In summary, liver transplantation offers the chance of immediate, complete, and definitive treatment in those patients with massive hepatomegaly secondary to diffuse PCLD. In these patients, fenestration and resection only offers temporary palliation, puts them at risk for potential morbidity and mortality, and jeopardizes the chances of further definitive treatment by transplantation. Several other series and their results are 
Table 3 Liver Transplantation for polycystic liver disease

\begin{tabular}{|c|c|c|c|c|c|}
\hline Author & No. of patients & Previous surgical procedure & Combined liver/Kidney Tx & Mortality & Mean follow-up (mo) \\
\hline Kwok $^{[65]}$ & 1 & 1 & 1 & 1 & - \\
\hline Starzl ${ }^{[53]}$ & 4 & 0 & 1 & 2 & 26 \\
\hline $\operatorname{Uddin}^{[54]}$ & 3 & 0 & 0 & 0 & NR \\
\hline Washburn $^{[55]}$ & 5 & 4 & 1 & 1 & 38 \\
\hline Lang $^{[56]}$ & 17 & 6 & 8 & 5 & 12 \\
\hline Swenson ${ }^{[58]}$ & 9 & 4 & 3 & 1 & 26 \\
\hline Pirenne $e^{[59]}$ & 16 & 4 & 1 & 2 & $18-120^{2}$ \\
\hline Takegoshi ${ }^{[60]}$ & $1^{1}$ & 0 & 0 & 0 & 8 \\
\hline Koyama $^{[61]}$ & $1^{1}$ & 0 & 0 & 0 & 18 \\
\hline Gustafsson $^{[63]}$ & 7 & 4 & 3 & 0 & 4 \\
\hline Becker $^{[62]}$ & 17 & NR & 17 & 3 & 49 \\
\hline Ueda $^{[64]}$ & $3^{1}$ & NR & 0 & 0 & 32 \\
\hline Kirchner $^{[66]}$ & 36 & NR & 15 & 5 & 62 \\
\hline
\end{tabular}

NR: Not reported. ${ }^{1}$ Indicates living-donor transplantation, ${ }^{2}$ Range of follow-up in months.

reviewed in Table 3.

As more patients undergo transplantation for PCLD, it is important to assess their long term outcomes, especially quality of life. Kirchner and colleagues reviewed the quality of life, via the SF-36 and a selfdesigned questionnaire, in 23 of 36 patients who underwent liver or combined liver-kidney transplantation for PCLD. Of the respondents, 91\% of patients felt "much better" or "better", while only 9\% felt "worse" than before. Fatigue, physical fitness, anorexia, vomiting, physical attractiveness, and interest in sex improved significantly after transplantation. Overall, patients with advanced PCLD have an improved quality of life after liver or combined liver-kidney transplantation ${ }^{[66]}$.

\section{CONCLUSION}

The management of patients with PCLD continues to be challenging. In the past several decades, there have been great advances in the knowledge of the pathogenesis, genetics, and effective treatment for PCLD. Understanding this disease, potential complications, associated medical conditions, and successful treatment strategies is essential for gastroenterologists and hepatobiliary surgeons. The ability to risk-stratify these patients by severity of disease can lead to earlier interventions and attempts at prevention of massive hepatomegaly that can be so debilitating. In patients with symptomatic PCLD, invasive management strategies should be based on the degree of symptoms, the severity of associated medical conditions, and the extent of their disease. Those symptomatic patients with large cysts or limited hepatic involvement would likely benefit from laparoscopic fenestration. Adequate hepatic resection with fenestration should be favored in patients with diffuse involvement of certain areas of hepatic parenchyma with remaining large areas of non-cystic parenchyma. Finally in the patient with diffuse, small cysts, transplantation is a valid option and should be pursued as primary therapy prior to development of debilitating disease that can increase complication rates.

\section{REFERENCES}

1 Bristowe F. Cystic disease of the liver associated with similar disease of the kidneys. Trans Pathol Soc Lond 1856; 7: 229-234

2 Vauthey JN, Maddern GJ, Blumgart LH. Adult polycystic disease of the liver. Br J Surg 1991; 78: 524-527

3 Grünfeld JP, Albouze G, Jungers P, Landais P, Dana A, Droz D, Moynot A, Lafforgue B, Boursztyn E, Franco D. Liver changes and complications in adult polycystic kidney disease. Adv Nephrol Necker Hosp 1985; 14: 1-20

4 Redston MS, Wanless IR. The hepatic von Meyenburg complex: prevalence and association with hepatic and renal cysts among 2843 autopsies corrected. Mod Pathol 1996; 9: 233-237

5 Grimm PC, Crocker JF, Malatjalian DA, Ogborn MR. The microanatomy of the intrahepatic bile duct in polycystic disease: comparison of the cpk mouse and human. J Exp Pathol (Oxford) 1990; 71: 119-131

6 Ramos A, Torres VE, Holley KE, Offord KP, Rakela J, Ludwig J. The liver in autosomal dominant polycystic kidney disease. Implications for pathogenesis. Arch Pathol Lab Med 1990; 114: 180-184

7 Perrone RD, Grubman SA, Rogers LC, Lee DW, Moy E, Murray SL, Torres VE, Jefferson DM. Continuous epithelial cell lines from ADPKD liver cysts exhibit characteristics of intrahepatic biliary epithelium. Am J Physiol 1995; 269: G335-G345

8 Kida T, Nakanuma Y, Terada T. Cystic dilatation of peribiliary glands in livers with adult polycystic disease and livers with solitary nonparasitic cysts: an autopsy study. Hepatology 1992; 16: 334-340

9 Gabow PA. Autosomal dominant polycystic kidney disease. $N$ Engl J Med 1993; 329: 332-342

10 Feldman M. Polycystic disease of the liver. Am J Gastroenterol 1958; 29: 83-86

11 Iglesias CG, Torres VE, Offord KP, Holley KE, Beard CM, Kurland LT. Epidemiology of adult polycystic kidney disease, Olmsted County, Minnesota: 1935-1980. Am J Kidney Dis 1983; 2: 630-639

12 D'Agata ID, Jonas MM, Perez-Atayde AR, Guay-Woodford LM. Combined cystic disease of the liver and kidney. Semin Liver Dis 1994; 14: 215-228

13 Gabow PA, Johnson AM, Kaehny WD, Manco-Johnson ML, Duley IT, Everson GT. Risk factors for the development of hepatic cysts in autosomal dominant polycystic kidney disease. Hepatology 1990; 11: 1033-1037

14 Sherstha R, McKinley C, Russ P, Scherzinger A, Bronner T, Showalter R, Everson GT. Postmenopausal estrogen therapy selectively stimulates hepatic enlargement in women with autosomal dominant polycystic kidney disease. Hepatology 1997; 26: 1282-1286

15 Berrebi G, Erickson RP, Marks BW. Autosomal dominant 
polycystic liver disease: a second family. Clin Genet 1982; 21: 342-347

16 Karhunen PJ, Tenhu M. Adult polycystic liver and kidney diseases are separate entities. Clin Genet 1986; 30: 29-37

17 Pirson Y, Lannoy N, Peters D, Geubel A, Gigot JF, Breuning $\mathrm{M}$, Verellen-Dumoulin C. Isolated polycystic liver disease as a distinct genetic disease, unlinked to polycystic kidney disease 1 and polycystic kidney disease 2. Hepatology 1996; 23: $249-252$

18 Iglesias DM, Palmitano JA, Arrizurieta E, Kornblihtt AR, Herrera M, Bernath V, Martin RS. Isolated polycystic liver disease not linked to polycystic kidney disease 1 and 2. Dig Dis Sci 1999; 44: 385-388

19 Reynolds DM, Falk CT, Li A, King BF, Kamath PS, Huston J, Shub C, Iglesias DM, Martin RS, Pirson Y, Torres VE, Somlo $\mathrm{S}$. Identification of a locus for autosomal dominant polycystic liver disease, on chromosome 19p13.2-13.1. Am J Hum Genet 2000; 67: 1598-1604

20 Drenth JP, Tahvanainen E, te Morsche RH, Tahvanainen P, Kääriäinen $\mathrm{H}$, Höckerstedt $\mathrm{K}$, van de Kamp JM, Breuning $\mathrm{MH}$, Jansen JB. Abnormal hepatocystin caused by truncating PRKCSH mutations leads to autosomal dominant polycystic liver disease. Hepatology 2004; 39: 924-931

21 van Erpecum KJ, Janssens AR, Terpstra JL, Tjon A Tham RT. Highly symptomatic adult polycystic disease of the liver. A report of fifteen cases. J Hepatol 1987; 5: 109-117

22 Korobkin M, Stephens DH, Lee JK, Stanley RJ, Fishman EK, Francis IR, Alpern MB, Rynties M. Biliary cystadenoma and cystadenocarcinoma: CT and sonographic findings. AJR Am J Roentgenol 1989; 153: 507-511

23 Que F, Nagorney DM, Gross JB, Torres VE. Liver resection and cyst fenestration in the treatment of severe polycystic liver disease. Gastroenterology 1995; 108: 487-494

24 Kabbej M, Sauvanet A, Chauveau D, Farges O, Belghiti J. Laparoscopic fenestration in polycystic liver disease. Br J Surg 1996; 83: 1697-1701

25 Gigot JF, Jadoul P, Que F, Van Beers BE, Etienne J, Horsmans Y, Collard A, Geubel A, Pringot J, Kestens PJ. Adult polycystic liver disease: is fenestration the most adequate operation for long-term management? Ann Surg 1997; 225: 286-294

26 Chauveau D, Fakhouri F, Grunfeld JP. Liver involvement in autosomal-dominant polycystic kidney disease: therapeutic dilemma. J Am Soc Nephrol 2000; 11: 1767-1775

27 Abascal J, Moya M, Martin F. Infection of hepatic cysts in polycystic disease. World J Surg 1984; 8: 424-425

28 Telenti A, Torres VE, Gross JB, Van Scoy RE, Brown ML, Hattery RR. Hepatic cyst infection in autosomal dominant polycystic kidney disease. Mayo Clin Proc 1990; 65: $933-942$

29 Yoshida H, Onda M, Tajiri T, Mamada Y, Taniai N, Mineta S, Hirakata A, Futami R, Arima Y, Inoue M, Hatta S, Kishimoto A. Infected hepatic cyst. Hepatogastroenterology 2003; 50: 507-509

30 Dmitrewski J, Olliff S, Buckels JA. Obstructive jaundice associated with polycystic liver disease. НРВ Surg 1996; 10: $117-120$

31 Chapman AB, Rubinstein D, Hughes R, Stears JC, Earnest MP, Johnson AM, Gabow PA, Kaehny WD. Intracranial aneurysms in autosomal dominant polycystic kidney disease. $N$ Engl J Med 1992; 327: 916-920

32 Geevarghese SK, Powers T, Marsh JW, Pinson CW. Screening for cerebral aneurysm in patients with polycystic liver disease. South Med J 1999; 92: 1167-1170

33 Qian Q, Li A, King BF, Kamath PS, Lager DJ, Huston J, Shub C, Davila S, Somlo S, Torres VE. Clinical profile of autosomal dominant polycystic liver disease. Hepatology 2003; 37: 164-171

34 Torra R, Nicolau C, Badenas C, Navarro S, Pérez L, Estivill X, Darnell A. Ultrasonographic study of pancreatic cysts in autosomal dominant polycystic kidney disease. Clin Nephrol 1997; 47: 19-22

35 Blyth H, Ockenden BG. Polycystic disease of kidney and liver presenting in childhood. J Med Genet 1971; 8: 257-284

36 Milutinovic J, Schabel SI, Ainsworth SK. Autosomal dominant polycystic kidney disease with liver and pancreatic involvement in early childhood. Am J Kidney Dis 1989; 13:
340-344

37 Andersson R, Jeppsson B, Lunderquist A, Bengmark S. Alcohol sclerotherapy of non-parasitic cysts of the liver. $\mathrm{Br}$ J Surg 1989; 76: 254-255

38 Kairaluoma MI, Leinonen A, Ståhlberg M, Päivänsalo M, Kiviniemi H, Siniluoto T. Percutaneous aspiration and alcohol sclerotherapy for symptomatic hepatic cysts. An alternative to surgical intervention. Ann Surg 1989; 210: 208-215

39 Tikkakoski T, Mäkelä JT, Leinonen S, Päivänsalo M, Merikanto J, Karttunen A, Siniluoto T, Kairaluoma MI. Treatment of symptomatic congenital hepatic cysts with single-session percutaneous drainage and ethanol sclerosis: technique and outcome. J Vasc Interv Radiol 1996; 7: 235-239

40 Lin TY, Chen CC, Wang SM. Treatment of non-parasitic cystic disease of the liver: a new approach to therapy with polycystic liver. Ann Surg 1968; 168: 921-927

41 Koperna T, Vogl S, Satzinger U, Schulz F. Nonparasitic cysts of the liver: results and options of surgical treatment. World J Surg 1997; 21: 850-854; discussion 854-855

42 Morino M, De Giuli M, Festa V, Garrone C. Laparoscopic management of symptomatic nonparasitic cysts of the liver. Indications and results. Ann Surg 1994; 219: 157-164

43 Martin IJ, McKinley AJ, Currie EJ, Holmes P, Garden OJ. Tailoring the management of nonparasitic liver cysts. Ann Surg 1998; 228: 167-172

44 Katkhouda N, Hurwitz M, Gugenheim J, Mavor E, Mason RJ, Waldrep DJ, Rivera RT, Chandra M, Campos GM, Offerman S, Trussler A, Fabiani P, Mouiel J. Laparoscopic management of benign solid and cystic lesions of the liver. Ann Surg 1999; 229 460-466

45 Fiamingo P, Tedeschi U, Veroux M, Cillo U, Brolese A, Da Rold A, Madia C, Zanus G, D'Amico DF. Laparoscopic treatment of simple hepatic cysts and polycystic liver disease. Surg Endosc 2003; 17: 623-626

46 Marks J, Mouiel J, Katkhouda N, Gugenheim J, Fabiani P. Laparoscopic liver surgery. A report on 28 patients. Surg Endosc 1998; 12: 331-334

47 Turnage RH, Eckhauser FE, Knol JA, Thompson NW. Therapeutic dilemmas in patients with symptomatic polycystic liver disease. Am Surg 1988; 54: 365-372

48 Henne-Bruns D, Klomp HJ, Kremer B. Non-parasitic liver cysts and polycystic liver disease: results of surgical treatment. Hepatogastroenterology 1993; 40: 1-5

49 Soravia C, Mentha G, Giostra E, Morel P, Rohner A. Surgery for adult polycystic liver disease. Surgery 1995; 117: 272-275

50 Vons C, Chauveau D, Martinod E, Smadja C, Capron F, Grunfeld JP, Franco D. Liver resection in patients with polycystic liver disease. Gastroenterol Clin Biol 1998; 22: 50-54

51 Hansman MF, Ryan JA, Holmes JH, Hogan S, Lee FT, Kramer D, Biehl T. Management and long-term follow-up of hepatic cysts. Am J Surg 2001; 181: 404-410

52 Yang GS, Li QG, Lu JH, Yang N, Zhang HB, Zhou XP. Combined hepatic resection with fenestration for highly symptomatic polycystic liver disease: A report on seven patients. World J Gastroenterol 2004; 10: 2598-2601

53 Starzl TE, Reyes J, Tzakis A, Mieles L, Todo S, Gordon R. Liver transplantation for polycystic liver disease. Arch Surg 1990; 125: 575-577

54 Uddin W, Ramage JK, Portmann B, Wilson P, Benjamin I, Tan KC, Williams R. Hepatic venous outflow obstruction in patients with polycystic liver disease: pathogenesis and treatment. Gut 1995; 36: 142-145

55 Washburn WK, Johnson LB, Lewis WD, Jenkins RL. Liver transplantation for adult polycystic liver disease. Liver Transpl Surg 1996; 2: 17-22

56 Lang H, von Woellwarth J, Oldhafer KJ, Behrend M, Schlitt HJ, Nashan B, Pichlmayr R. Liver transplantation in patients with polycystic liver disease. Transplant Proc 1997; 29: 2832-2833

57 Jeyarajah DR, Gonwa TA, Testa G, Abbasoglu O, Goldstein R, Husberg BS, Levy MF, Klintmalm GB. Liver and kidney transplantation for polycystic disease. Transplantation 1998; 66: 529-532

58 Swenson K, Seu P, Kinkhabwala M, Maggard M, Martin P, 
Goss J, Busuttil R. Liver transplantation for adult polycystic liver disease. Hepatology 1998; 28: 412-415

59 Pirenne J, Aerts R, Yoong K, Gunson B, Koshiba T, Fourneau I, Mayer D, Buckels J, Mirza D, Roskams T, Elias E, Nevens F, Fevery J, McMaster P. Liver transplantation for polycystic liver disease. Liver Transpl 2001; 7: 238-245

60 Takegoshi K, Tanaka K, Nomura H, Miyagi K, Taira S, Takayanagi N. Successful living donor liver transplantation for polycystic liver in a patient with autosomal-dominant polycystic kidney disease. J Clin Gastroenterol 2001; 33: 229-231

61 Koyama I, Fuchinoue S, Urashima Y, Kato Y, Tsuji K, Kawase T, Murakami T, Tojimbara T, Nakajima I, Teraoka S. Living related liver transplantation for polycystic liver disease. Transpl Int 2002; 15: 578-580

62 Demirci G, Becker T, Nyibata M, Lueck R, Bektas H, Lehner F, Tusch G, Strassburg C, Schwarz A, Klempnauer J, Nashan B. Results of combined and sequential liver-kidney transplantation. Liver Transpl 2003; 9: 1067-1078

63 Gustafsson BI, Friman S, Mjornstedt L, Olausson M, Backman
L. Liver transplantation for polycystic liver disease-indications and outcome. Transplant Proc 2003; 35: 813-814

64 Ueda M, Egawa H, Oike F, Taira K, Uryuhara K, Fujimoto Y, Kozaki K, Tanaka K. Living-donor liver transplantation for polycystic liver disease. Transplantation 2004; 77: 480-481

65 Kwok MK, Lewin KJ. Massive hepatomegaly in adult polycystic liver disease. Am J Surg Pathol 1988; 12: 321-324

66 Kirchner GI, Rifai K, Cantz T, Nashan B, Terkamp C, Becker T, Strassburg C, Barg-Hock H, Wagner S, Lück R, Klempnauer $\mathrm{J}$, Manns MP. Outcome and quality of life in patients with polycystic liver disease after liver or combined liver-kidney transplantation. Liver Transpl 2006; 12: 1268-1277

67 Sanchez H, Gagner M, Rossi RL, Jenkins RL, Lewis WD, Munson JL, Braasch JW. Surgical management of nonparasitic cystic liver disease. Am J Surg 1991; 161: 113-118; discussion 118-119

68 Farges $\mathrm{O}$, Bismuth $\mathrm{H}$. Fenestration in the management of polycystic liver disease. World J Surg 1995; 19: 25-30

S- Editor Liu Y L- Editor Alpini GD E- Editor Yin DH 